\title{
Tomographic imaging of $P$ wave velocity structure beneath the region around Beijing*
}

\author{
Zhifeng Ding * Xiaofeng Zhou Yan Wu Guiyin Li and Hong Zhang \\ Institute of Geophysics, China Earthquake Administration, Beijing 100081, China
}

\begin{abstract}
The three-dimension crustal and upper mantle structures in the region around Beijing were studied by seismic tomography. We used the $\mathrm{P}$ wave arrival times from local and teleseismic events. These events were recorded by 250 stations of the North China Seismic Array and 108 stations of the Beijing Telemetry Seismic Network. 118869 P wave arrivals from 10285 local events and $12189 \mathrm{P}$ wave arrivals from 107 teleseismic events were used in the inversion. We obtained the 3-D P wave velocity structure of the crust and upper mantle with the horizontal resolution of $0.3^{\circ}$ in the studied region. The tomographic imaging shows the remarkably heterogeneous velocity variation. The velocity anomalies are in well agreement with the geological structure in the shallow crust. The different relationships between seismic activities and velocity anomalies may imply the different seismogenic structure and mechanism. Beneath the Moho under Taihangshan mountain and Yanshan mountain, we found the high velocity anomalies deep to $120 \mathrm{~km}$ and $200 \mathrm{~km}$, respectively. The deep high velocity zone may be explained by the existence of the mountain root under Yanshan mountain. The high velocity anomalies in the upper mantle of North China basin may be the relics of the de-rooting from the former craton mantle lithosphere.
\end{abstract}

Key words: crustal and upper mantle structure; Beijing; seismic tomography CLC number: P315. $3^{+}$Document code: A

\section{Introduction}

The present studied region is around Beijing city, with the area of latitude between $36^{\circ} \mathrm{N}$ and $42^{\circ} \mathrm{N}$, longitude between $112^{\circ} \mathrm{E}$ and $120^{\circ} \mathrm{E}$. The studied region is located in the northern part of North China, and stretches over the blocks of North China basin, Taihangshan mountain and Yanshan mountain (Figure 1). The North China basin is in the eastern part of the region, and the basin is characterized by alternate Tertiary uplift and depression zones in NNE direction. The Taihangshan and Yanshan mountain are in the uplift area. The seismic active zones distribute mainly along the NNE structures in the basin area, Shanxi rift, and the WNW-trending Zhangjiakou-Bohai seismic zone.

The seismic activities were strong in this region during the past several hundred years. The 1679 Sanhe-Pinggu M8.0 earthquake occurred only $50 \mathrm{~km}$ away from Beijing city. The 1976 Tangshan M7.8 earthquake destroyed the city of Tangshan in several seconds, and caused the large amount of losses of people and properties. The recent strong earthquakes in this region also include the 1966 Xingtai earthquake $\left(M_{\mathrm{S}} 7.2\right), 1969$ Bohai earthquake $\left(M_{\mathrm{S}} 7.4\right), 1998$ Zhangbei earthquake $\left(M_{\mathrm{S}} 6.2\right), 2006$ Wen'an earthquake $\left(M_{\mathrm{S}} 5.1\right)$, and so on. The investigation of the crustal and upper mantle structures and the seismotectonics is very important for us to understand the physical processes of inter-continent earthquakes and to mitigate the seismic hazard.

Because of the political and economic importance for the capital area, many scholars investigated the 3-D seismic velocity structure models in this region by using P wave arrival times (Jin et al, 1980; Liu et al, 1986, 1989; Zhu et al, 1990; Sun and Liu, 1995; Ding, 1999; Yu et al, 2003; Huang and Zhao, 2005; Lei et al, 2008). With the increasing seismic observatories and the improvement of the coverage of the seismic stations, especially installation of the seismic array in North China, the collected seismic dataset supplies more complete database. This paper tries to obtain detailed and reliable 3-D seismic velocity structure by using the seismic tomography method.

\footnotetext{
* Received 12 June 2009; accepted in revised form 14 July 2009; published 10 August 2009.

^ Corresponding author. e-mail: zhfding@vip.sina.com
} 


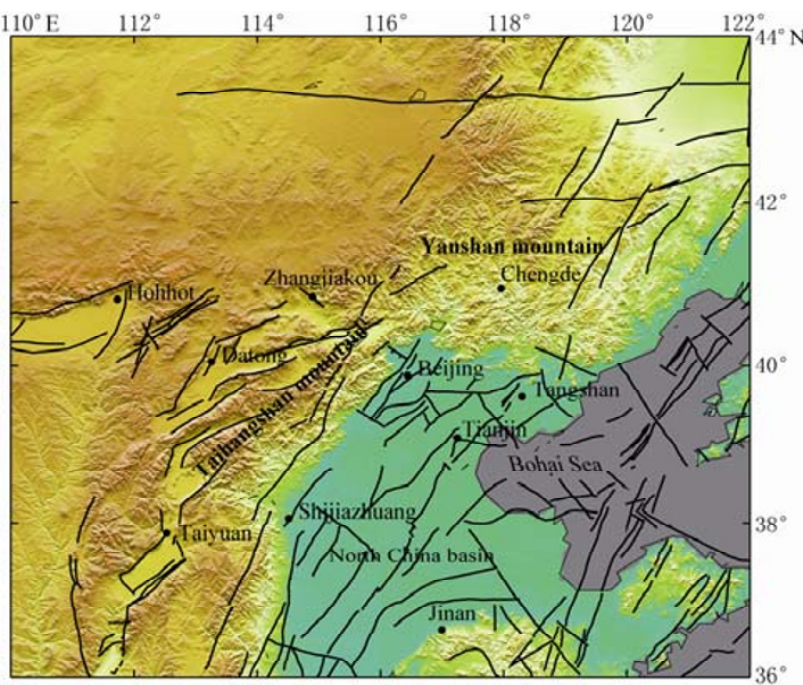

Figure 1 Background structures of the studied region.

\section{Data and method}

In the studied region, Beijing Telemetry Seismic Network, which is the densest seismic network in Chinese mainland, covers the Beijing area with 108 stations. The recording system of these stations was improved to be digitized in 2003. In October of 2006, the temporary stations of North China Seismic Array were installed around Beijing region. This array is comprised of 200 broadband seismometers well-distributed in the studied region with the station interval of about $30 \mathrm{~km}$, and 50 short period seismometers around Tangshan area. Combined the seismic network and the seismic array, a dense seismic observatory system was built around Beijing.

The local seismic events were located in the orientation of NNE in North China basin, Taihangshan mountain, and the WNW along Zhangjiakou-Bohai seismic belt. Figure 2 shows the location of the used seismic stations and the epicenters of the local events from 1976 to 2007. We collect the 118869 seismic P wave arrivals of 10285 local seismic events recorded by the seismic stations in the research region.

The teleseismic $\mathrm{P}$ wave arrivals were picked from the digital recordings of the seismic array. The distribution of the teleseismic events is shown in Figure 3. We obtained $12189 \mathrm{P}$ wave arrivals from 114 teleseismic events with the epicentral distances between $30^{\circ}$ and $90^{\circ}$ away from Beijing. The azimuth of the teleseismic events distributed in all the four quadrants. The good coverage of seismic stations makes a well-distribution of seismic rays at different depths in the crust and upper mantle of the studied region (see Figure 4).

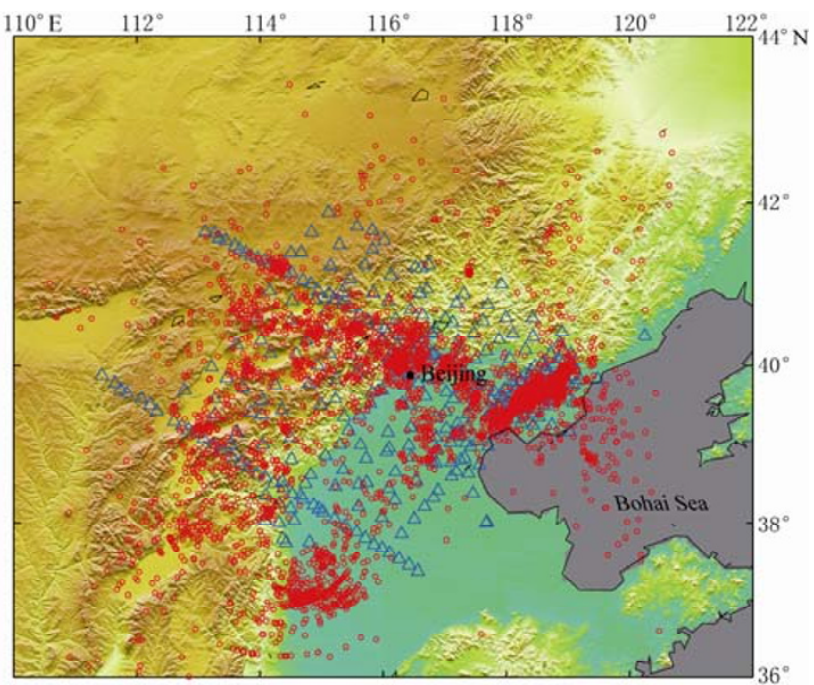

Figure 2 Location of the seismic stations and distribution of the local events from 1976 to 2007. Triangles stand for the stations and circles for the epicenters of local events.

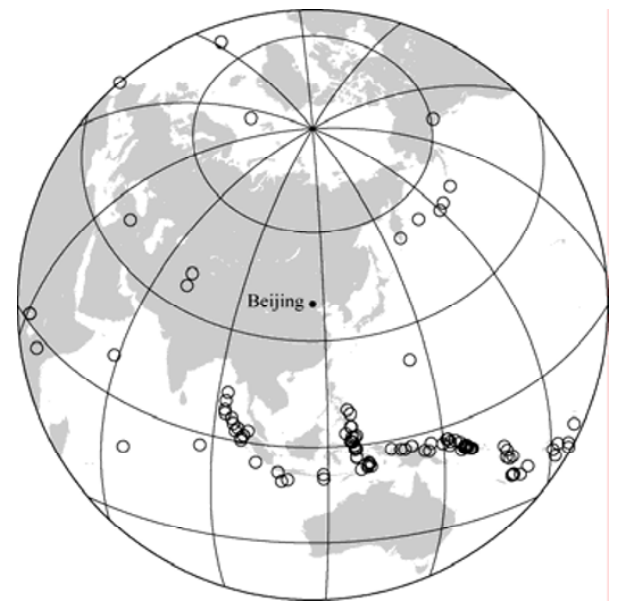

Figure 3 Epicenters of the used teleseismic events. Circles represent the events.

We used the tomography method of Zhao et al $(1992,1994)$ to inverse the 3-D crustal and upper mantle structure by using the local and teleseismic arrival times. This method is adaptable to the seismic velocity structure which includes complex velocity discontinuities, such as Conrad and Moho. 3-D grid net is used to represent the heterogeneous velocity structures. The 3-D ray tracing technique is employed the pseudo-bending technique (Um and Thurber, 1987) in layers and Snell's law across the discontinuities. The velocity perturbations at the grid nodes are calculated to reduce the travel time residuals between the calculated and observed data. The LSQR algorithm (Paige and Saunders, 1982) with damping and smoothing is used to conduct the inversions 


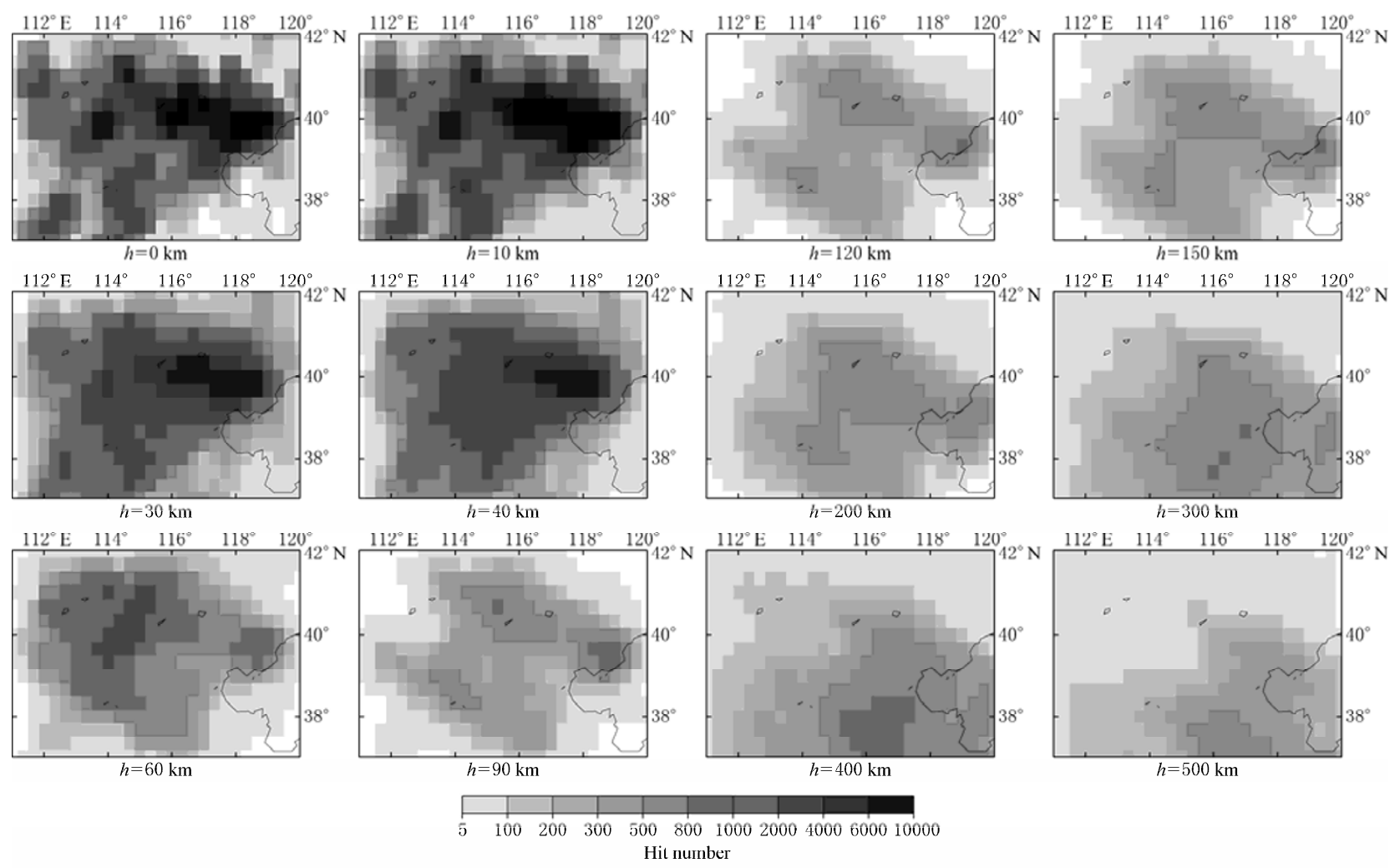

Figure 4 Distribution of hit number of seismic rays in different depths. $h$ denote depth same as that in Figures 5 and 6.

of the observation equations. The nonlinear tomographic problem is solved by iteratively conducting linear inversions.

\section{Analysis and results}

Checkerboard tests were conducted to evaluate the adequacy of the ray coverage and spatial resolution (Zhao et al, 1992, 1994). To conduct the checkerboard test, we first built the velocity checkerboard model with the alternative positive and negative velocity anomalies assigned to the 3-D grid nodes. The amplitudes of the anomalies were set to $3 \%$ for all the nodes. The synthetic travel times, which were exactly associated to the real event and recording and station dataset, were calculated for the checkerboard model. Starting from the 1-D layered structure, the synthetic data were used to inverse the 3-D structure. The resolution was considered to be good for the areas where the checkerboard model can be well reconstructed. After several testing, we found the special resolution is generally good for the grid space $0.33^{\circ}$ (as shown in Figure 5). The resolution is higher than the previous researches because of good coverage both from the stations of the seismic network and the seismic array. The good resolution in the shallow crust and uppermost mantle is benefited by good coverage of the seismic stations and head waves from Moho discontinuity.

The results of deep seismic sounding give the well constrains of the depth variation of Moho discontinuities (Jia et al, 2005; Zhang et al, 1998; Li et al, 2001). The depths of Moho discontinuities were fixed during the tomography procedures.

Strong $\mathrm{P}$ wave velocity variations can be found in the tomography imaging (Figure 6), indicating the existence of the heterogeneous structure in the crust and upper mantle of Beijing region. In the shallow slices (depth is 0 and $10 \mathrm{~km}$ ) we can see the pattern of velocity anomalies associated with geological structure. Tangshan is in low velocity zone of the upper crust. The velocity of Taihangshan and Yanshan mountains are high in upper crust. Bohai Sea and the western Taihangshan mountain (Shanxi rift zone) are in low velocity zone. The velocities of the mountain areas are relatively low in the lower crust. In the upper mantle, the high velocity beneath Taihangshan mountain can be traced down to the depth of $120 \mathrm{~km}$. In Yanshan mountain, the strong high velocity zone can also be found down to the depth of $200 \mathrm{~km}$. Bohai Sea is characterized by the low 

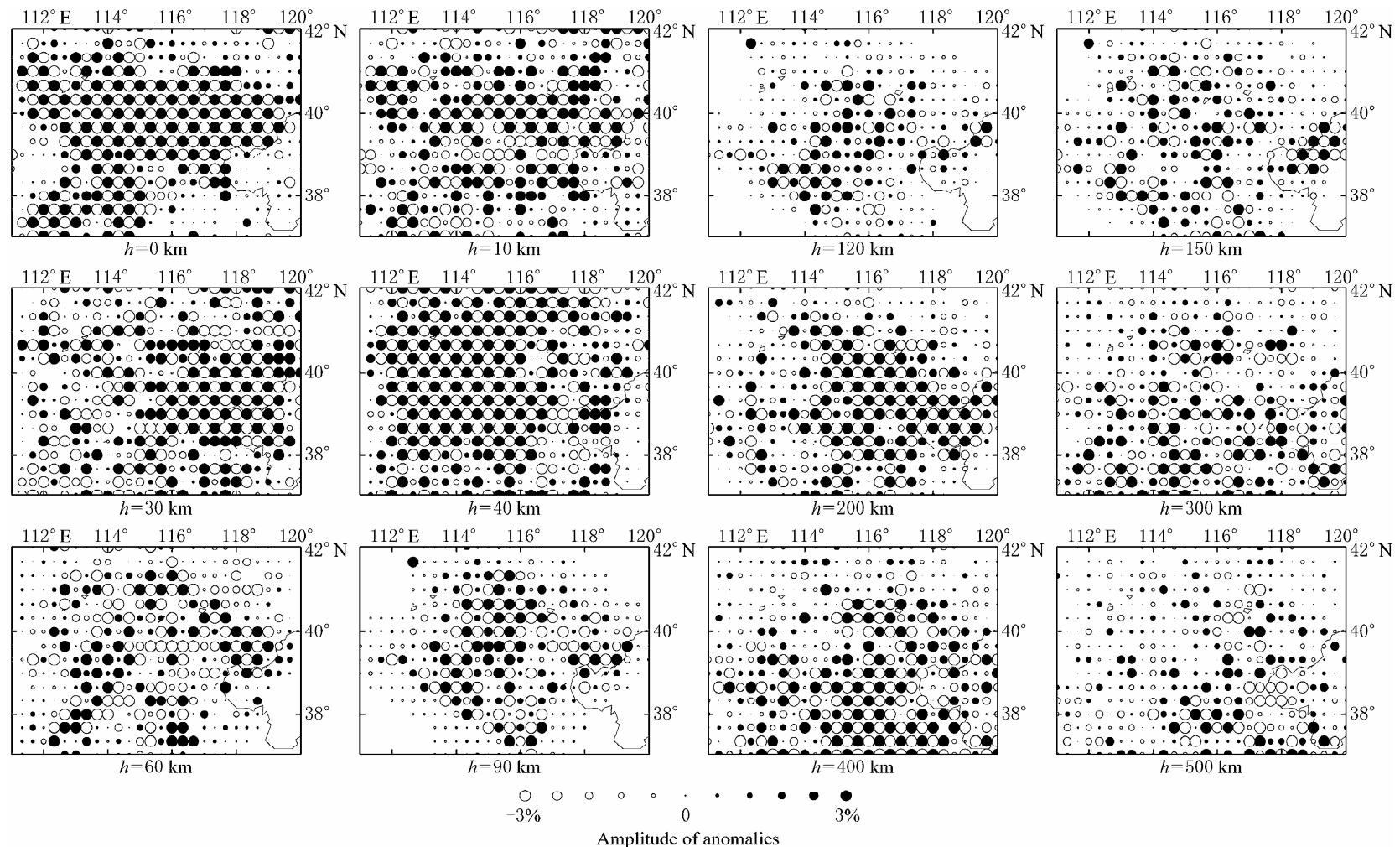

Figure 5 Checkerboard test for the grid space of $0.33^{\circ}$.
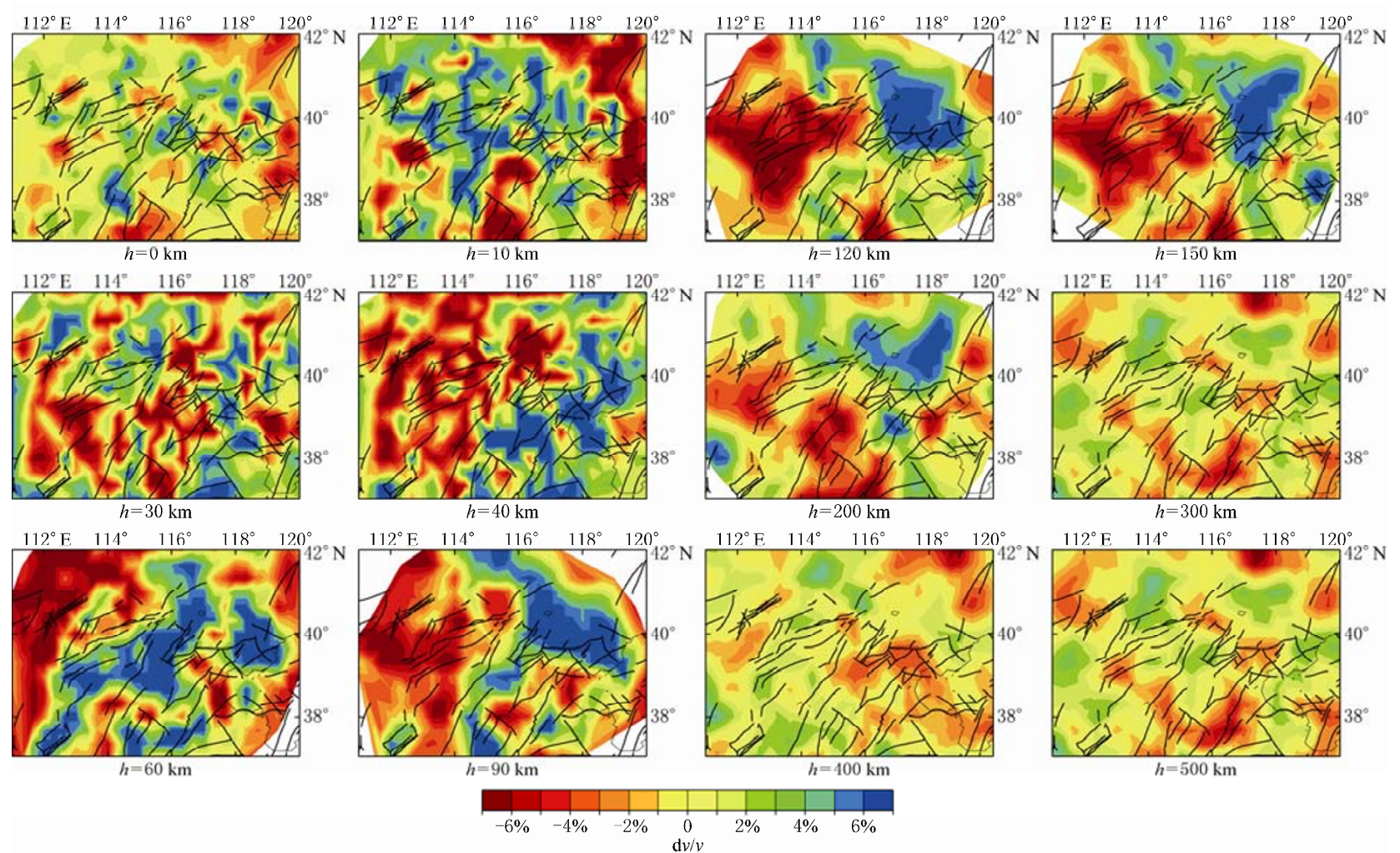

Figure $6 \mathrm{P}$ wave tomography results for the region around Beijing. 
velocity zone above the depth of $90 \mathrm{~km}$.

\section{Discussion and conclusions}

The heterogeneity of the crust and upper mantle in North China was found in the early tomography researches (Jin et al, 1980; Liu et al, 1986). With the increasing amount of seismic recordings and the better coverage of stations in the research region, inversion ability and resolution were improved (Huang and Zhao, 2004, 2009; Wang et al, 2008). The permanent seismic stations were designed to well-control the accurately locating the local earthquakes, and they were mainly installed near the seismic active area. To obtain the ideal tomography results, the best way is to use the dense and even distribution of the observed stations. The installation of seismic array is the best choice to satisfy the requirement.

The earthquakes in this region are mainly located in Zhangjiakou-Bohai seismic belt, North China basin and western Taihangshan mountain. Figure 7 gives the comparison of the epicenters of local events and the $\mathrm{P}$ wave anomalies of the slice at the depth of $10 \mathrm{~km}$. The earthquakes occurred in the high velocity zones from Zhangjiakou to Tangshan area. The location of the earthquakes in North China basin and western Taihangshan mountain are in the transitional zone between high and low velocity. The seismogenic zones are in the low velocity area in Bohai Sea. The difference correspondences of the seismic activity zone and the seismic velocity anomalies might mean different mechanism of the earthquake occurrences in different structure background.

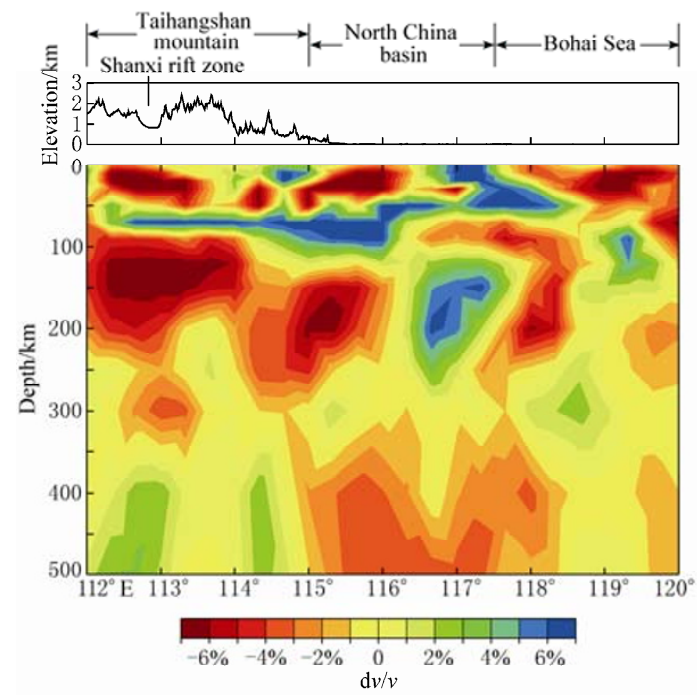

Figure 8 Cross section along the latitude of $39^{\circ} \mathrm{N}$.
The North China basin and western Taihangshan mountain belong to extensive tectonic structures. The high heat flow in Bohai Sea and the low velocity anomalies means the heat activity in the seismogenic zone.

Figure 8 shows a cross section along the latitude of $39^{\circ} \mathrm{N}$ that passes through the Taihangshan mountain, North China basin and Bohai Sea. The high velocity anomalies can be found beneath Taihangshan mountain and the uplift area in North China basin in crust. The crust of Shanxi rift zone, depression zone of North China basin and Bohai Sea are in low velocity anomalies. The image of the velocity anomalies in mantle agrees with a model of destruction of North China craton (Deng et al,

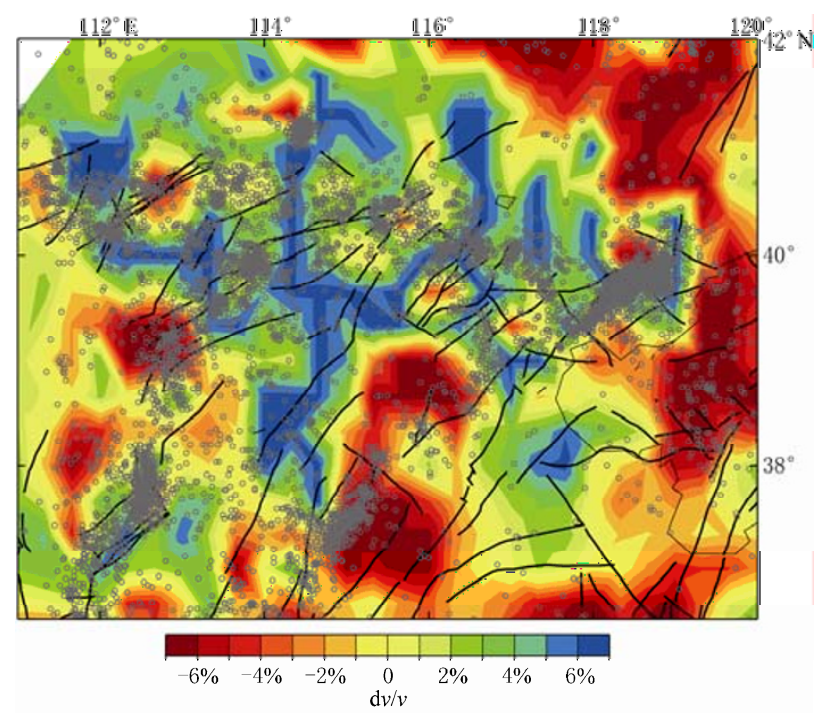

Figure 7 Epicenters and the $\mathrm{P}$ wave velocity anomaly slice at the depth of $10 \mathrm{~km}$.

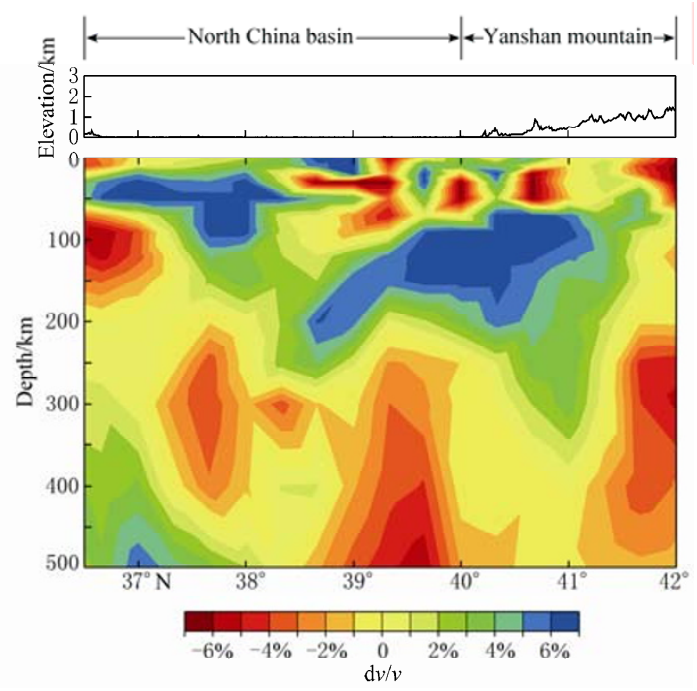

Figure 9 Cross section along the longitude of $117^{\circ} \mathrm{E}$. 
1994). An anomalous high velocity block in the upper mantle of the North China basin may be associated with the sinking relics from the former mantle lithosphere.

The cross section along the longitude of $117^{\circ} \mathrm{E}$ (Figure 9) shows us the deep high velocity anomalies in upper mantle of the Yanshan mountain which could be traced deeper than $200 \mathrm{~km}$. This indicates that the destruction of the craton did not affect Yanshan mountain. The lithosphere has normal thickness in this area.

The seismic $\mathrm{P}$ wave arrivals for local and teleseismic events from the recordings of North China Seismic Array and Beijing Telemetry Seismic Network were collected for the inversion of 3-D crust and upper mantle structure around the Beijing.

After the analysis of the checkerboard test, we conducted the tomographic imaging with horizontal resolution of $0.3^{\circ}$, and obtained the 3-D structure of $\mathrm{P}$ wave velocity anomalies.

The velocity anomalies are in well agreement with the geological structure in the shallow crust. Taihangshan mountain and Yanshan mountain area are with the high velocity, the Bohai Sea with low velocity. The Shanxi rift and the depression areas in North China basin are in low velocity zone.

The different relationships between seismic activities and velocity anomalies may correspond to the different seismogenic mechanism.

In the uppermost mantle beneath the eastern Taihangshan mountain and Yanshan mountain, we found the high velocity anomalies deep to $120 \mathrm{~km}$ and $200 \mathrm{~km}$, respectively. The deep high velocity zone under Yanshan mountain may indicate existence of the mountain root.

The high velocity anomalies in the upper mantle of North China basin may be associated with the relics of de-rooting from the ancient Craton mantle lithosphere.

Acknowledgements This study was supported by the National Special Fund of Science and Technological Basic Work under grant No. 2006FY110100, and partially by the 2007 Special Fund of Seismological Industry "Seismic Travel Time Table in the Capital Area" under grant No. 200708009. Contribution No. is 09FE3003 of Institute of Geophysics, China Earthquake Administration. Thanks Prof. Dapeng Zhao for providing the seismic tomography codes. All the figures in this work are made by the software of GMT (Wessel and Smith, 1995).

\section{References}

Deng J, Mo X, Zhao H, Luo Z and Du Y (1994). Lithosphere root/derooting and activation of the East China continent. Geoscience 8(3): 349-356 (in Chinese with English abstract).

Ding Z F (1999). Local Seismic Tomography: Theory and Applications. Ph D Dissertation, Institute of Geophysics, China Seismological Bureau, Beijing, 58-100 (in Chinese with English abstract).

Huang J L and Zhao D (2004). Crustal heterogeneity and seismotectonics of the region around Beijing, China. Tectonophysics 385: 159-180.

Huang J L and Zhao D (2005). Three dimensional P wave velocity structure in Capital area and deep tectonic surroundings for the evolution of strong earthquakes. Chinese Science Bulletin 50(4): 348-355 (in Chinese).

Huang J L and Zhao D (2009). Seismic imaging of the crust and upper mantle under Beijing and surrounding regions. Phys Earth Planet Inter 173(3-4): 330-348.

Jia S, Qi C, Wang F, Chen Q, Zhang X and Chen Y (2005). Three dimensional crustal gridded structure of the Capital area. Chinese J Geophys 48(6): 1316-1 324 (in Chinese with English abstract).

Jin A, Liu F and Sun Y (1980). 3-D P wave velocity structure of crustal and upper mantle in Beijing area. Chinese J Geophys 23(2): 172-182 (in Chinese with English abstract).

Lei J, Xie F, Lan C, Xing C and Ma S (2008). Seismic image under the Beijing region inferred from $\mathrm{P}$ and $\mathrm{PmP}$ data. Phys Earth Planet Inter 162(3-4): $165-185$.

Li S, Zhang X, Song Z, Shi J, Deng H, Yang J, Zhang C and Ren Q (2001). Three-dimensional crustal structure of the capital area obtained by a joint inversion of deep seismic sounding data from multiple profiles. Chinese $J$ Geophys 44(3): 360-368 (in Chinese with English abstract).

Liu F, Qu K and Wu F (1986). Seismic tomography in North China. Chinese J Geophys 29(5): 442-449 (in Chinese with English abstract).

Liu F, Qu K, Wu F, Li Q, Liu J and Hu G (1989). Seismic tomography in the continent of China and the surrounding areas. Chinese J Geophys 32(3): 281-291 (in Chinese with English abstract).

Paige C and Saunders M (1982). LSQR: an Algorithm for sparse linear equations and sparse least squares. Assoc Comput Meth Trans Math Software 8: 43-71.

Sun R and Liu F (1995). Crustal structures and occurrence of strong earthquake in Beijing-Tianjin-Tangshan area, I. P wave velocity structure. Chinese J Geophys 38(5): 599-607 (in Chinese with English abstract).

Um J and Thurber C (1987). A fast algorithm for two-point seismic ray tracing. Bull Seism Soc Amer 77: 972-986.

Wang Z S, Wang C Y, Zeng R S and Wang X L (2008). Tomographic imaging of $\mathrm{P}$ and $\mathrm{S}$ wave velocity structure beneath North China and its vicinity. $C T$ Theory and Application 17(2): 15-27 (in Chinese with English abstract).

Wessel P and Smith W (1995). New version of the generic mapping tools released. EOS Trans $A G U$ 76: 329.

Yu X, Chen Y and Wang P (2003). Three dimensional P wave velocity structure in Beijing-Tianjin-Tangshan area. Acta Seismologica Sinica 16(1): 1-15.

Zhang X, Zhu Z and Zhang C (1998). Study of the crust and upper mantle structure in and around the Zhangjiakou-Bohai seismic belt. In: Institute of Geology, State Seismological Bureau ed. Active Fault Research (6). Seismological Press, Beijing, 1-16 (in Chinese).

Zhao D, Hasegawa A and Horiuchi S (1992). Tomographic imaging of P and S wave velocity structure beneath northeastern Japan. $J$ Geophys Res 97: 19 909-19 928.

Zhao D, Hasegawa A and Kanamori H (1994). Deep structure of Japan subduction zone as derived from local, regional and teleseismic events. $J$ Geophys Res 99: 22 313-22 329.

Zhu L, Zeng R and Liu F (1990). Three-dimensional P wave velocity structure under the Beijing network area. Chinese J Geophys 33(3): 267-277 (in Chinese with English abstract). 